\title{
PELATIHAN PEMBUATAN KERAJINAN TANGAN "BUKET" UNTUK MENINGKATKAN KREATIVITAS SISWA SMK MAWADDAH
}

\author{
Oleh: \\ Qurrotul Aini ${ }^{1}$, Tony Yulianto ${ }^{2}$, Faisol ${ }^{3}$ \\ 1,2,3Fakultas MIPA Universitas Islam Madura \\ 1qurrotul188@gmail.com
}

\begin{abstract}
Abstrak
SMK Mawaddah merupakan salah satu sekolah menengah kejuruan swasta yang memiliki satu jurusan yaitu pemasaran. Produk yang dipasarkan bermacam-macam, namun semua produknya lebih dominan ke produk kuliner, dan masih kurang mewadahi bagi siswa yang memiliki keahlian di bidang kesenian/kerajinan. Oleh karena itu dibuatlah pelatihan pembuatan kerajinan tangan ini agar siswa bisa mengembangkan kreativitasnya dan juga hasil produknya nanti bisa juga menjadi tambahan produk yang dipasarkan. Adapun contoh kerajinan tangan yang dipilih adalah buket. Tingkat pemahaman siswa SMK Mawaddah $50 \%$ sudah banyak yang memahami, $40 \%$ sudah sangat paham, dan hanya $10 \%$ yang tidak paham. Kemampuan siswa rata-rata Banyak yang memahami meskipun masih ada sedikit yang sulit memahami pelatihan ini. Sehingga pelatihan ini bisa dikatakan berhasil dan dapat diterapkan dalam pengolahan produk yang akan dipasarkan.
\end{abstract}

Kata Kunci: Buket, Kerajinan Tangan, Kreativitas

\section{Abstract}

SMK Mawaddah is a private vocational high school that has one department, namely marketing. The products that are marketed vary, but all of the products are more dominant in culinary products, and are still not sufficient for students who have expertise in the arts / crafts. Therefore, training on making handicrafts was made so that students could develop their creativity and also the results of their products could also be additional products to be marketed. The example of handicraft chosen is a bouquet. The level of understanding of SMK Mawaddah students is 50\%, many already understand, $40 \%$ are very understanding, and only $10 \%$ do not understand. Average ability of students Many understand, although there are still a few who find it difficult to understand this training. So that this training can be said to be successful and can be applied in the processing of products to be marketed.

Keywords:Bouquet, Crafts, Creativity

\section{PENDAHULUAN}

Kreativitas merupakan kemampuan seseorang berfikir dan bertingkah laku. Seseorang yang memiliki kreativitas atau kemampuan berfikir divergensi yang tinggi tidak banyak kesulitan dalam memecahkan masalah yang dihadapinya. Oleh karena itu, kreativitas yang didefinisikan para ahli selalu berkaitan dengan kemampuan berfikir dan bertingkah laku. Mengasah kreativitas sangat diperlukan karena pentingnya bagi keberhasilan seseorang. Kreativitas bukan hanya milik seniman, tetapi semua aspek kehidupan akan memerlukan kemampuan kreativitas untuk mengatasi masalah dan mendapatkan ide-ide yang memperbaiki karir, bisnis, dan hidupnya. Kreativitas menjaga gairah hidup dan kreativitas menjadikan hidup terus melaju (Ali \& Sari, 2013).

Kerajinan/kriya adalah jenis karya seni rupa terapan (seni pakai) yang umumnya dihasilkan melalui kerja terampil para perajinnya. Usaha untuk menciptakan suatu produk atau barang yang dilakukan dengan tangan dan memiliki fungsi pakai atau keindahan sehingga memiliki nilai jual. Peluang usaha handicraft (kerajinan tangan) juga cukup menjanjikan untuk menghasilkan keuntungan. Di Indonesia sendiri banyak kerajinan tangan yang cukup terkenal hingga ke negara lain. Dengan kreativitas yang dimilikki oleh seseorang sebuah benda yang tadinya tidak terlihat bernilai jual menjadi indah dan bahkan bisa memiliki nilai jual yang tinggi (Gusmania \& Amelia, 2019).

Di SMK Mawaddah memiliki satu jurusan yaitu pemasaran. Produk yang dipasarkan bermacam-macam, namun semua produknya lebih dominan ke produk kuliner, dan masih kurang mewadahi bagi siswa yang memiliki keahlian di bidang kesenian/kerajinan. Oleh karena itu dibuatlah pelatihan pembuatan kerajinan tangan agar siswa bisa mengembangkan kreativitasnya dan juga 
hasil produknya nanti bisa juga menjadi tambahan produk yang dipasarkan.

Adapun kerajinan tangan yang dipilih adalah buket. Buket merupakan sebuah kerajinan tangan yang saat ini lebih banyak diminati khususnya dikalangan remaja, tidak hanya itu saat ini buket juga banyak digunakan sebagai hadiah ataupun simbol ucapan selamat. Buket ini terbuat dari kain flanel, spunbond dan lem. Selain menggunakan kain flanel buket ini juga bisa menggunakan makanan seperti coklat, permen, dan lain-lain. Jenis kerajinan ini dipilih karena bahan bakunya mudah didapatkan dan harganya sangat terjangkau.

Kain flanel atau felt adalah jenis kain yang dibuat dari serat wol, tanpa ditenun. Flanel merupakan jenis kain tertua dalam sejarah manusia, lebih tua dari kain tenun dan rajut. Jenis kain flanel yang sangat rumit juga ditemukan dalam kondisi diawetkan di sebuah makam di Siberia yang berasal dari tahun 600 M (Gusmania \& Amelia, 2019).

\section{METODE PENGABDIAN}

Metode yang digunakan adalah pelatihan terhadap kurang lebih 25 siswa. Kegiatan ini dimulai dengan mengidentifikasi tingkat pengetahuan dan kreativitas siswa dengan cara memberikan sedikit teori terhadap siswa, baru setelah itu melakukan praktik pelatihan langsung terhadap siswa.

\section{Waktu dan Tempat}

Waktu pelaksanaan kegiatan pelatihan pada tanggal 03 September sampai dengan 12 September. Tempat pelaksanaan di SMK Mawaddah Kec.Palengaan Kab.Pamekasan. Rincian kegiatan bisa dilihat pada Tabel 1.

Tabel 1. Rincian kegiatan

\begin{tabular}{|l|l|l|}
\hline Tahap & Tanggal & Tempat \\
\hline $\begin{array}{l}\text { Tahapan } \\
\text { awal }\end{array}$ & $\begin{array}{l}\text { 03 dan 05 } \\
\text { September }\end{array}$ & $\begin{array}{l}\text { Di kelas X B } \\
\text { SMK } \\
\text { Mawaddah }\end{array}$ \\
\hline $\begin{array}{l}\text { Tahapan } \\
\text { pelaksanaan }\end{array}$ & $\begin{array}{l}\text { 07-09 } \\
\text { september }\end{array}$ & $\begin{array}{l}\text { Aula SMK } \\
\text { Mawaddah }\end{array}$ \\
\hline $\begin{array}{l}\text { Tahapan } \\
\text { monitoring } \\
\text { dan evaluasi }\end{array}$ & $\begin{array}{l}10 \text { dan 12 } \\
\text { september }\end{array}$ & $\begin{array}{l}\text { Di aula SMK } \\
\text { Mawaddah }\end{array}$ \\
\hline
\end{tabular}

\section{Metode dan Rancangan \\ * Tahapan Awal}

Hari pertama dan hari kedua ini dimulai dengan memberikan sedikit materi mengenai proses pembuatan kerajinan tangan dari kain flanel.

\section{* Tahapan Pelaksanaan}

Pada tahap pelaksanaan ini hari pertama dimulai dengan pengenalan bahan dan alatalat yg digunakan yang terdiri dari kain flanel, spounbond, lem dan lain-lain.

Hari kedua dilanjut dengan pembelian bahan dan alat-alat yang dibutuhkan tadi meliputi kain flanel, spunbond dan lain-lain.

Hari ketiga disini dilanjut dengan pembuatan pola dan pemotongan kain flanel dan spunbond menjadi beberapa bagian, setelah itu baru dibentuk menjadi sebuah bunga hingga bentuk-bentuk lainnya, dan terakhir ditempel di spunbond dan di lem.

\section{* Tahapan Monitoring dan Evaluasi}

Tahap ini untuk hari pertama dikemas dengan pengumpulan dan pengecekan hasil pelatihan tadi.

Hari kedua disini mengevaluasi siapa saja yang bisa dikatakan mampu dalam pelatihan tersebut.

\section{Pengambilan Sampel}

Pengambilan sampel diambil dari hasil pelatihan 2 siswa yang sudah cukup bagus dalam melakukan pelatihan tersebut. Hasil bisa dilihat pada Gambar 1.

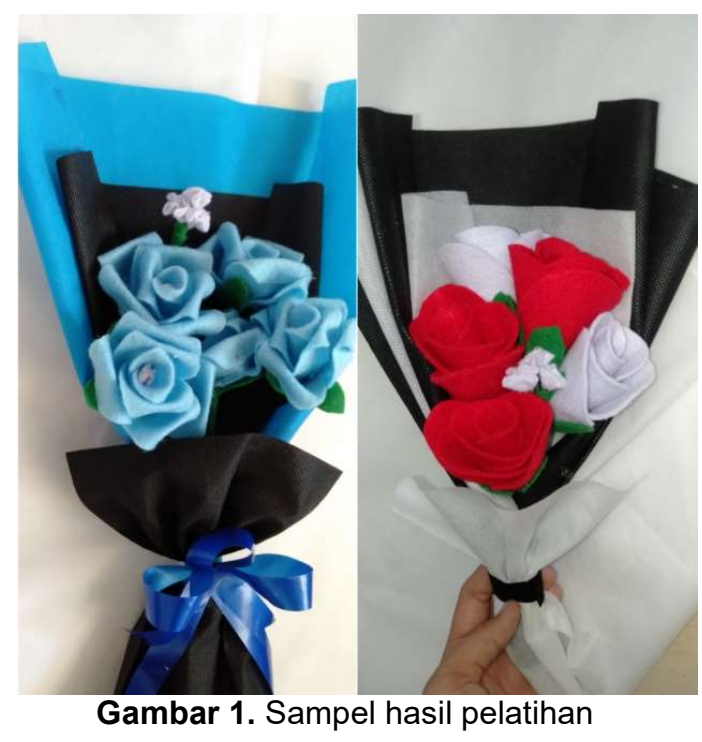

\section{HASIL DAN PEMBAHASAN}

Sebelum melalukan pelatihan kerajinan tangan ini diadakan rapat atau diskusi kecil dengan pihak sekolah mengenai pelatihan ini, pihak sekolah merespon dan mendukung dengan baik karena selama ini di SMK 
Mawaddah tidak ada yang melakukan pelatihan kerajinan, Siswa SMK Mawaddah dari dulu Cuma di latih pengolahan kuliner sampai ke pemasarannya namun mereka tidak pernah dilatih dalam proses pembuatan kerajinan tangan, oleh karena itu pihak sekolah sangat mendukung dan merespon baik kegiatan pelatihan ini.

Tahap awalnya diberikan penjelasan kepada siswa SMK Mawaddah mengenai proses pembuatan suatu produk, Produk yang diterapkan dalam pelatihan ini yaitu kerajinan tangan berupa "BUKET".

Tahap kedua melakukan pengenalan dan pemilihan alat dan bahan kepada siswa SMK Mawaddah, bahan yang cocok dengan jenis buket yang akan mereka buat yaitu:

1. Kain flanel dimana kain ini sangat cocok apabila ingin membuat kerajinan yang terbuat dari kain. Contoh kain flanel bisa dilihat padaa Gambar 2.

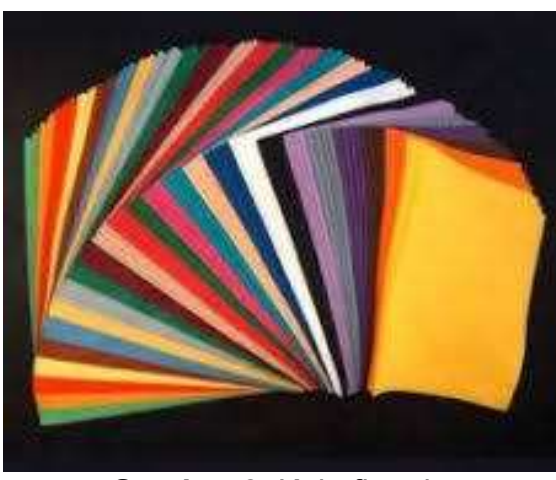

Gambar 2. Kain flanel

2. Bahan yang kedua yaitu kain spunbond dimana kain ini sangat cocok untuk dijadikan bagian luar dari kerajinan tangan (Buket) tersebut, kain ini bisa di gunakan dalam segala jenis buket seperti buket bunga, buket cokelat, buket snack dan untuk jenis jenis buket lainnya. Contoh spunbond bisa dilihat pada Gambar 3.

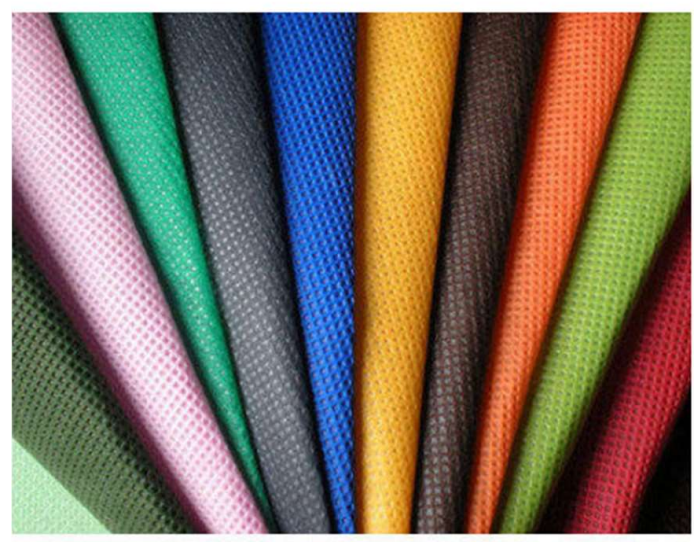

Gambar 3. spunbond

Adapun alat yang digunakan yaitu :

1) Gunting untuk memotong bahan

2) pensil dan penggaris untuk membuat pola

3) lem tembak

contoh alat yang digunakan bisa dilihat pada Gambar 4.

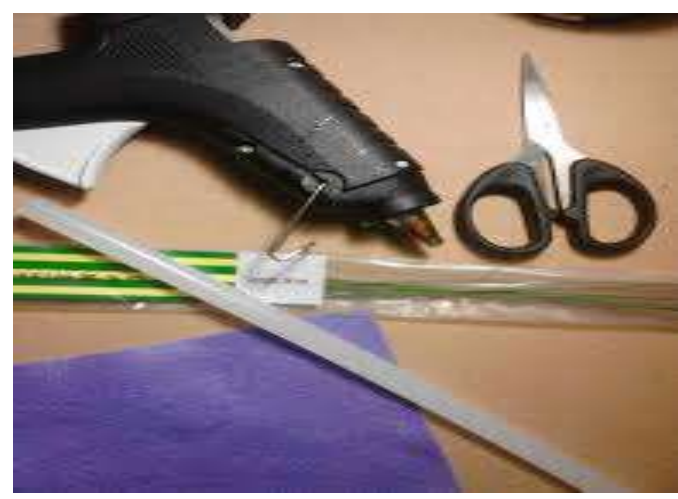

Gambar 4. Alat yang digunakan

Tahap yang ketiga yaitu tahap pembelian alat dan bahan ke toko atau pasar.

Tahap yang ke empat yaitu tahap pembuatan pola dimana tahapan ini dijelaskan dan diberikan contoh pola terlebih dahulu kemudain siswa diperintahkan untuk membuat pola sesuai dengan pemikirannya sendiri.

Tahap yang kelima yaitu pemotongan kain flanel dimana tahapan ini kain ini dipotong sesuai dengan pola yang sudah di buat tadi. Pemotongan pola dapat dilihat pada Gambar 5. 


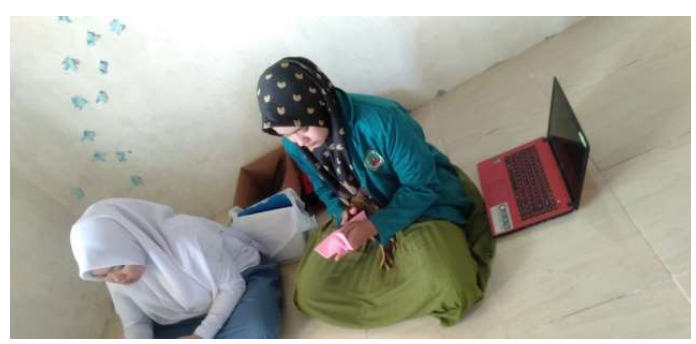

Gambar 5. Pemotongan pola

Tahap yang ke enam yaitu perekatan kain flanel menggunakan lem tembak sesuai dengan bentuk yang diinginkan dimana tahapan ini siswa dibimbing agar hasilnya sesuai dengan bentuk yang mereka inginkan. Prosesnya bisa dilihat pada Gambar 6 .

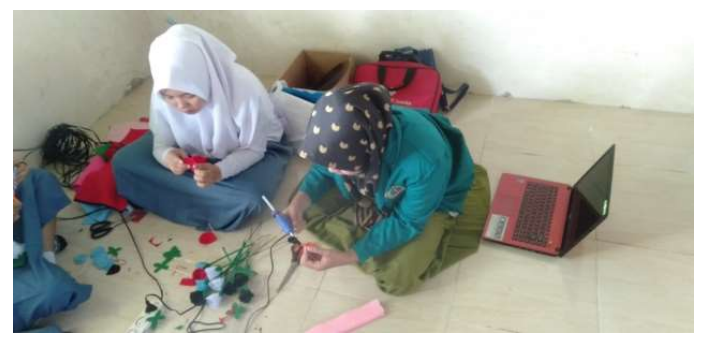

Gambar 6. Proses pengeleman

Tahap yang ke tujuh yaitu tahap packing dimana tahapan ini merupakan tahapan terakhir dari proses pembuatan produk kerajinan tangan ini. Hasil packing dapat dilihat pada Gambar 7.

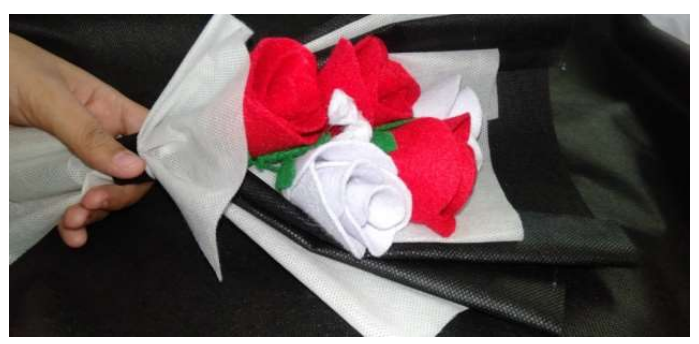

Gambar 7. Hasil packing

Secara keseluruhan program pelatihan ini mendapatkan respon yang sangat positif dari siswa khususnya kepala sekolah di SMK Mawaddah. Dengan adanya program ini, siswa merasa sangat aktif melalui kegiatan yang sifatnya positif, dan tentunya dapat memberikan tambahan pengetahuan (Ukkas, 2018).

Selanjutnya, untuk mendukung hal tersebut maka kesinambungan kegiatan ini harus diciptakan. Untuk itu dirumuskan beberapa item rencana kegiatan yang merupakan tindak lanjut dari kegiatan ini antara lain sebagai berikut: a. Mengukur sejauh mana tingkat ketercapaian target dari kegiatan pelatihan ini, yaitu dengan melakukan pemantauan terhadap siswa yang telah mengikuti pelatihan. Ketika peserta sudah mengaktualisasikan tentang apa yang didapatkan selama pelatihan maka dianggap bahwa kegiatan ini telah mencapai target yang diharapkan. Begitu pun sebaliknya.

b. Menemukan cara dan solusi yang tepat terhadap siswa yang belum paham dan mengerti dalam pelatihan ini. disebabkan oleh kendala-kendala tertentu, misalnya dari segi pengetahuan dan lain-lain. (Ukkas, 2018).

Untuk mengetahui tingkat keberhasilan pelaksanaan pelatihan pembuatan kerajinan tangan ini bisa dilihat pada Gambar 8 berikut:

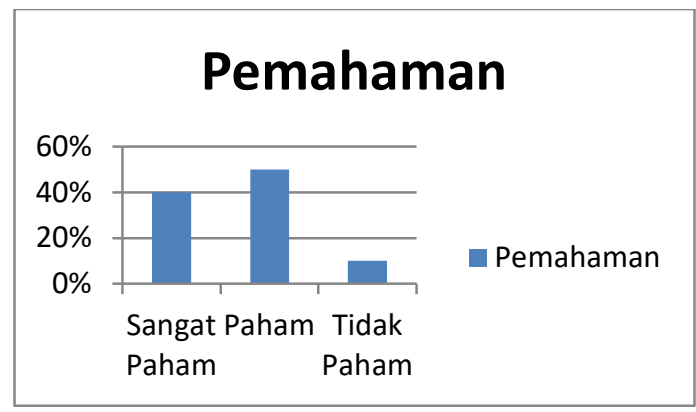

Gambar 8. Persentase Hasil Pemahaman Siswa

Berdasarkan Gambar 8, tingkat pemahaman siswa SMK Mawaddah 50\% sudah banyak yang memahami, $40 \%$ sudah sangat paham, dan hanya $10 \%$ yang tidak paham. Kemampuan siswa rata-rata Banyak yang memahami meskipun masih ada sedikit yang sulit memahami pelatihan ini. Sehingga pelatihan ini bisa dikatakan berhasil dan dapat diterapkan dalam pengolahan produk yang akan dipasarkan.

\section{SIMPULAN DAN SARAN}

Kesimpulan dari penjelasan tersebut bahwa pelatihan kerajinan tangan sangat di perlukan bagi siswa SMK Mawaddah agar siswa bisa menuangkan pemikiran mereka dalam seni/kerajinan tangan dan juga mampu membuat kerajinan tangan yang banyak diminati oleh kalangan remaja. Tingkat pemahaman siswa SMK Mawaddah 50\% sudah banyak yang memahami, $40 \%$ sudah sangat paham, dan hanya $10 \%$ yang tidak paham. Kemampuan siswa rata-rata Banyak 
yang memahami meskipun masih ada sedikit yang sulit memahami pelatihan ini. Sehingga pelatihan ini bisa dikatakan berhasil dan dapat diterapkan dalam pengolahan produk yang akan dipasarkan.

Saran yang diberikan kepada kepala sekolah agar bisa terus mendukung kreativitas dan memberikan wadah/pelatihan kepada siswa SMK Mawaddah agar siswa bisa mengembangkan kemampuannya dibidang seni/kerajinan tangan dan kreativitas lainnya, dan juga kepada siswa agar lebih mengembangkan kreativitasnya bukan hanya kerajinan tangan yang berupa buket saja melainkan kerajinan lainnya, seperti gantungan kunci, miniatur atau yang lainnya.

\section{UCAPAN TERIMA KASIH}

Terimakasih yang pertama kepada kepala sekolah SMK Mawaddah yang telah memberi izin atas terselenggaranya pelatihan ini. Yang kedua kepada dosen pembimbing dan juga kepada pihak-pihak yang telah membantu. Dan terakhir kepada LPPM Universitas Islam Madura.

\section{DAFTAR PUSTAKA}

Ali, M., \& Sari, D. O. (2013). Pelatihan Kerajinan Tangan Dari Kain Flanel Sebagai Pemberdayaan. Seri Pengabdian Masyarakat, 2(2), 137.

Gusmania, Y., \& Amelia, F. (2019). Pendampingan Pembuatan Kerajinan Tangan Dari Kain Flanel Untuk Menunjang Perekonomian Keluarga Sebagai Usaha Kecil Menengah (UKM) Masyarakat Di Kelurahan Sei Langkai. Minda Baharu, 3(1), 59-65.

Ukkas, I. (2018). Pengembangan SDM Berbasis Pelatihan Keterampilan Dan Perbedayaan Pemuda. Prosiding Seminar Nasional, 3(1), 120-352. 